\title{
EL INTERNAMIENTO DE LOS COLONOS ALEMANES DEL CAMERÚN EN LA GUINEA ESPAÑOLA (1915-1919)
}

\author{
EduARDo GonZÁlez CALLeja ${ }^{146}$ \\ (Universidad Carlos III de Madrid)
}

Resumen: El territorio español que sufrió más de cerca los avatares de la guerra naval y terrestre y las tensiones diplomáticas derivadas de la Primera Guerra mundial fueron las posesiones de Guinea. El artículo relata los esfuerzos de las autoridades especialmente el gobernador general Ángel Barrera Luyando- por salvaguardar la integridad territorial de la colonia, evitando las incursiones de uno y otro bando, y los problemas planteados por los miles de alemanes y nativos que buscaron refugio en Guinea y luego en la Península tras la ocupación aliada del Camerún a inicios de 1916.

Palabras clave: Camerún, España, Guinea española, Primera Guerra Mundial, Refugiados.

AвsтRACt: The Spanish territory that suffered closer the vicissitudes of naval and land warfare and diplomatic tensions arising from the First World War were the possessions of Guinea. The article reports on the efforts of the authorities, especially the Governor General Ángel Barrera Luyando, to safeguard the territorial integrity of the colony, preventing incursions by both sides, and the problems posed by the thousands of Germans and natives who sought refuge in Guinea and then in the Peninsula after the Allied occupation of Cameroon in early 1916.

KeYwords: Cameroon, Spain, Spanish Guinea, Refugees, WWI.

\footnotetext{
146 Departamento de Humanidades: Historia, Geografía y Arte, Facultad de Humanidades, Comunicación y Documentación, Universidad Carlos III de Madrid, c/ Madrid, no 128, 28903 Getafe (Madrid).
} 
La Gran Guerra se libró en lugares remotos, muy alejados de las metrópolis, y en ocasiones la conflagración implicó casi de manera directa a las potencias neutrales que tenían posesiones próximas a las zonas de combate del escenario colonial, especialmente en África. El territorio español que sufrió más de cerca los avatares de la guerra naval y terrestre y las tensiones diplomáticas derivadas del conflicto fueron las posesiones de Guinea. Del 6 al 25 de agosto de 1914, franceses, belgas y británicos atacaron la colonia alemana del Camerún desde sus respectivas colonias del África Ecuatorial, Congo y Nigeria, e impusieron un bloqueo naval de sus costas a partir de la medianoche del 23 de abril de 1915 (DANE, 1919: 43-63; NERÍN, 2010: 67-70) ${ }^{147}$. Una columna francesa procedente de Gabón se apoderó del Camerún meridional, operando peligrosamente cerca del territorio de Río Muni, lo que produjo algunos roces entre las autoridades coloniales españolas y las fuerzas militares germanas ${ }^{148}$. La falta de control del territorio por parte de los españoles propició que los contendientes aprovecharan el vacío de soberanía para irrumpir repetidas veces por la frontera. Para evitar esta situación, el gobernador general de la colonia, capitán de navío Ángel Barrera Luyando, desplegó en mayo de 1915 cinco destacamentos en la frontera del río Muni, con Mikomeseng como puesto más avanzado, pero su débil dotación — no más de una treintena de hombres en total— no parecía la más adecuada para salvaguardar la integridad territorial de la colonia, evitando las incursiones de uno y otro bando. A fines de ese año, las fuerzas de la Entente ocuparon la meseta central de la colonia alemana, expulsando a sus enemigos hacia la frontera de la Guinea espańola. Para evitar interferencias por parte de los aliados, Ángel Barrera (que se mantuvo en el cargo de gobernador general desde 1910 a 1924) dio órdenes a la Administración de Hacienda y Aduanas de la capital Santa Isabel, Elobey y Bata, para que se extremase la vigilancia sobre la carga que se desembarcaba, de manera que se disipase cualquier duda de que se estaba efectuando contrabando de guerra a favor de los combatientes

147 Nota del Ministère des Affaires Étrangères al embajador español marqués de Valtierra (París 22-IV-1915), en AGA, Asuntos Exteriores, Embajada en París, leg. 54/5937, y nota del embajador británico Arthur H. Hardinge al ministro de Estado marqués de Lema (Madrid, 24-II-1915), en AHN, Asuntos Exteriores, Fondo Política, Serie I Guerra Mundial, leg. H.3134, declarando el bloqueo británico de la costa del África Oriental alemana desde medianoche del 28-II. En la medianoche del 23-IV-1915 se realizó la nueva declaración de bloqueo de las costas de Camerún, que fue levantado el 8-III-1916, tras la total conquista del territorio.

148 Carta del gobernador imperial de Camerún, Karl Ebermaier, al gobernador general de las posesiones españolas en el Golfo de Guinea, capitán de navío Ángel Barrera Luyando (Yaundé, 1-VII-1915), en AHN, Asuntos Exteriores, Fondo Política, Serie I Guerra Mundial, leg. H.2890, donde denuncia la circulación de tropas aliadas por territorio español. 
alemanes ${ }^{149}$. El 30 de abril de 1915, el administrador de aduanas informó que se había efectuado contrabando de guerra con destinatario desconocido en cuatro cajas procedentes de Sevilla que contenían 37.509 cartuchos de fusil Máuser. De nuevo el 6 de mayo se produjo la incautación de 2.155 cartuchos y otros efectos de guerra. En una carta al ministro de Estado, Barrera se quejaba de la nota intimidatoria que le había remitido el 6 de agosto el jefe de las fuerzas aliadas, general Charles Dobell, quien le acusaba de tolerar el paso de suministros de toda clase por territorio español con destino a las fuerzas alemanas del Camerún. El gobernador se justificó señalando que eran actividades de particulares, pero las protestas anglo-francesas por estas circunstancias se mantuvieron por largo tiempo, generando enojosos incidentes en el tráfico comercial ${ }^{150}$. De hecho, los cruceros aliados que patrullaban las costas del Camerún habían desviado y visitado el 27 y 30 de junio los vapores Antonico e Isla de Panay en el Golfo de Guinea (Suelaba, Camerún), incautándose de mercancías que llevaban a bordo ${ }^{151}$. Este último barco, que ya había sido objeto de visitas poco amistosas el 7 y 17 de noviembre de 1914 en su trayecto de Bata a Fernando Poo (en cuyo transcurso los aliados detuvieron a un súbdito alemán), fue detenido el 27 de junio de 1915 casi a la vista de Santa Isabel, lo que motivó la protesta del ministro de Estado al embajador francés ${ }^{152}$. El 11 de marzo de 1916, el Isla de Panay fue retenido en Dakar por las autoridades francesas, que confiscaron 691 bultos propiedad de José Villarroya y Benedicto, procedentes de un país neutral (el puerto de Buenos Aires) y dirigidos a otro neutral. El buque Ciudad de Cádiz, que hacía la ruta de la península y Canarias a Fernando Poo, había sido detenido el 23 de marzo de 1915, cuando estaba a punto de llegar a Santa Isabel, por llevar 1.575 sacos de arroz a la casa alemana Moritz. Este mismo barco también fue obligado a atracar en Dakar el 4 de diciembre de $1916^{153}$.

149 Barrera a ministro de Estado marqués de Lema (Santa Isabel de Fernando Poo, 11-VI-1915), en AGA, Asuntos Exteriores, Embajada en París, leg. 54/5942.

150 Barrera al ministro de Estado marqués de Lema (Santa Isabel de Fernando Poo, 23-VIII-1915), en AHN, Asuntos Exteriores, Fondo Política, Serie I Guerra Mundial, leg. H.2890.

151 Ministère des Affaires Étrangères a marqués de Valtierra (París, 30-VIII-1915) en AGA, Asuntos Exteriores, Embajada en París, leg. 54/5942.

152 Ministro de Estado marqués de Lema a embajador francés Geoffray (San Sebastián, 18-VIII-1915), en AGA, Asuntos Exteriores, Embajada en París, leg. 54/5942.

153 Embajador espańol marqués del Muni a ministre des Affaires Étrangères Aristide Briand (París, 8-XII-1916) en AGA, Asuntos Exteriores, Embajada en París, leg. 54/5948. 
Tras la caída de Yaundé en manos aliadas el 1 de enero de 1916, los alemanes se retiraron hacia la frontera del Río Muni. A partir del 4 de febrero, un millar de militares y civiles alemanes se dispusieron a refugiarse en territorio español, acompañados de unos 45.000 cameruneses, entre ellos áskaris, familiares, criados y jefes tribales. Tras el paso oficial de la frontera el 15 de febrero, el 20 el gobernador imperial Karl Ebermaier envió sendos telegramas a Berlín y Madrid en los que confirmaba la caída de la colonia (NERÍN, 2010: 70) ${ }^{154}$. Los militares alemanes y nativos fueron tratados amigablemente por los españoles, que sólo tenían 180 soldados en Río Muni. La conquista final de Camerún generó otro tipo de problemas. Barrera decidió devolver en dirección a la colonia capturada a todos los cargadores y criados del Ejército alemán, con lo que más de 25.000 cameruneses fueron reexpedidos en contra de su voluntad al territorio controlado por los aliados. Tras no pocas presiones, el 3 de febrero Barrera, con el apoyo del Ministerio de Estado y de la Embajada española en Londres llegó al acuerdo de internar a los refugiados a Fernando Poo, y evacuar a los alemanes a Espańa a la primera oportunidad. Un millar de alemanes (400 de ellos militares), 6.000 áskaris y 9.000 civiles (otras fuentes hablan de 5.621 soldados y 11.850 civiles, incluidas numerosas mujeres, niños y criados) fueron instalados en tres campos: uno establecido en el hospital y dos en el barrio de las Caracolas de Santa Isabel (BLANCA CARLIER, 1976: $140)^{155}$. Las condiciones higiénicas y alimentarias eran tan frágiles que murieron 1.031 refugiados, y la epidemia de "gripe española" que brotó en mayo de 1916 volvió a diezmar a los emigrantes (NERÍN, 2010: 77).

Los campos tenían una organización militar que corrió a cargo de los oficiales y los suboficiales alemanes. Ante el peligro que constituía esta fuerza desarmada pero aún encuadrada dentro de la disciplina castrense, pronto comenzaron las presiones aliadas para su anulación como fuerza armada efectiva: Francia y Gran Bretaña solicitaron la reclusión de los miles de soldados nativos refugiados, y exigieron que los sesenta oficiales alemanes del contingente fueran trasladados a la península a la mayor brevedad posible. Hacia marzo se envió desde Marruecos una compañía de Infantería de Marina del Regimiento Expedicionario de Larache. En esos mismos días, los vapores Cataluña e Isla de Panay, escoltados por el crucero Extremadura, condujeron a un importante contingente de civiles y militares hacia España. Tras hacer escala en Canarias, llegaron a Cádiz el 5 de mayo en medio de una gran

154 Sobre este personaje, véase la semblanza de HOFFMANN (2006).

155 Véase "Día político, Los alemanes en la Guinea Española", El Liberal, 11-II-1916, sobre el internamiento de unos 900 soldados alemanes refugiados en la Guinea española con sus familias. Otras fuentes hablaban de 1.299 soldados, que debían ser enviados a Mallorca. 
expectación, y a continuación fueron trasladados a Madrid ${ }^{156}$. Eran 856 refugiados (incluidos el gobernador imperial Karl Ebermaier, el jefe militar coronel Karl Zimmermann y el etnólogo Günther Tessmann), de los que 21 no embarcaron por enfermedad. Lo hicieron 244 miliares en activo, 200 empleados civiles combatientes, 88 particulares combatientes, 40 empleados civiles no combatientes y 283 particulares no combatientes, en buena parte ancianos, mujeres y nińos. Existe otra lista sin fechar por orden alfabético con su destino de internamiento en España. Muchos colonos, e incluso el jefe del pueblo nativo Beti, fijaron su residencia en Madrid, donde pudieron sobrevivir con recursos procedentes de la Embajada alemana, si bien un número no determinado fue trasladado desde Espańa hacia la neutral Holanda, y de ahí a Alemania. antes del final de la guerra (MOBERLY, 1931: 412) ${ }^{157}$.

Además de los sacerdotes, religiosos, médicos y personal civil, que fijaron libremente su residencia en la Península (fue el caso de 18 eclesiásticos que permanecieron en el Puerto de Santa María y dos médicos en Cádiz, o dos sanitarios en Canarias), los alemanes refugiados fueron repartidos en tres centros: 200 en Alcalá de Henares (suboficiales y cabos), 217 en Pamplona (de los cuales dos capitanes, diez oficiales subalternos, cinco médicos, un consejero del gobernador de Camerún, 52 civiles, una dama, el jefe de la estación radiotelegráfica de Duala, tres criados y 142 suboficiales y soldados) y 380 en Zaragoza, en un contingente que comprendía treinta oficiales, 200 civiles y 150 suboficiales y soldados ${ }^{158}$. El antiguo gobernador del Camerún, Karl Ebermaier, se estableció en primera instancia en la capital aragonesa con dos de sus consejeros, 28 oficiales,

156 BORDEJÉ Y MORENCOS (1978), p. 278 y Ángel BARRERA LUYANDO, "Relación de los súbditos alemanes acogidos a esta Colonia, procedentes del Protectorado de Kamerun e internados en España en los vapores Isla de Panay y Cataluña" (Santa Isabel de Fernando Poo, 16-IV-1916), en AHN, Asuntos Exteriores, Fondo Política, Serie I Guerra Mundial, leg. H.3150. La llegada a Cádiz y de ahí por Sevilla y Jerez hasta la estación del Mediodía de Madrid el día 5-V-1916, donde les esperaba el embajador alemán príncipe de Ratibor y los agregados naval y militar Hans von Krohn y Arnold von Kalle, en TOJO RAMALLO y TOJO GONZÁLEZ (2008), pp. 69-78.

157 La discrepancia entre los 856 refugiados que llegaron a la Península y los 783 censados por la Subsecretaría del Ministerio de la Guerra puede obedecer a esta circunstancia.

158 La actitud admirativa de la población pamplonesa a la llegada de estos internados, y la acogida amistosa de la oficialidad de la guarnición, en informe de la Sûreté de Hendaya (5-VI-1916), en SHD, Marine, leg. SS Q 4. Según mensaje del adjunto al agregado naval, teniente de navío Antoine Fortoul (Madrid, 1-7-1918), en SHD, Marine, leg. SS Q 56, en el campo de Alcalá de Henares estarían encerrados entre 180 y 260 alemanes procedentes de Camerún. Según el estado de los alemanes internados en la 4a Región (6-III-1919), en AHN, Asuntos Exteriores, Fondo Política, Serie I Guerra Mundial, leg. H.3144, había 17 refugiados 
ocho médicos, 119 sanitarios, cincuenta soldados y 152 civiles. Luego, con el consentimiento del Gobierno español, fijó su residencia en Madrid, y solicitó infructuosamente a través de la Embajada alemana permisos para visitar periódicamente los lugares de internamiento de los súbditos alemanes ${ }^{159}$. En todo caso, mantuvo su liderazgo sobre los refugiados del Camerún hasta el final de la guerra. A tal fin, se constituyó ante las narices de la Policía española un auténtico gobierno imperial de Camerún en un local de la Legación alemana situado en la calle Fortuny no 3 de Madrid.
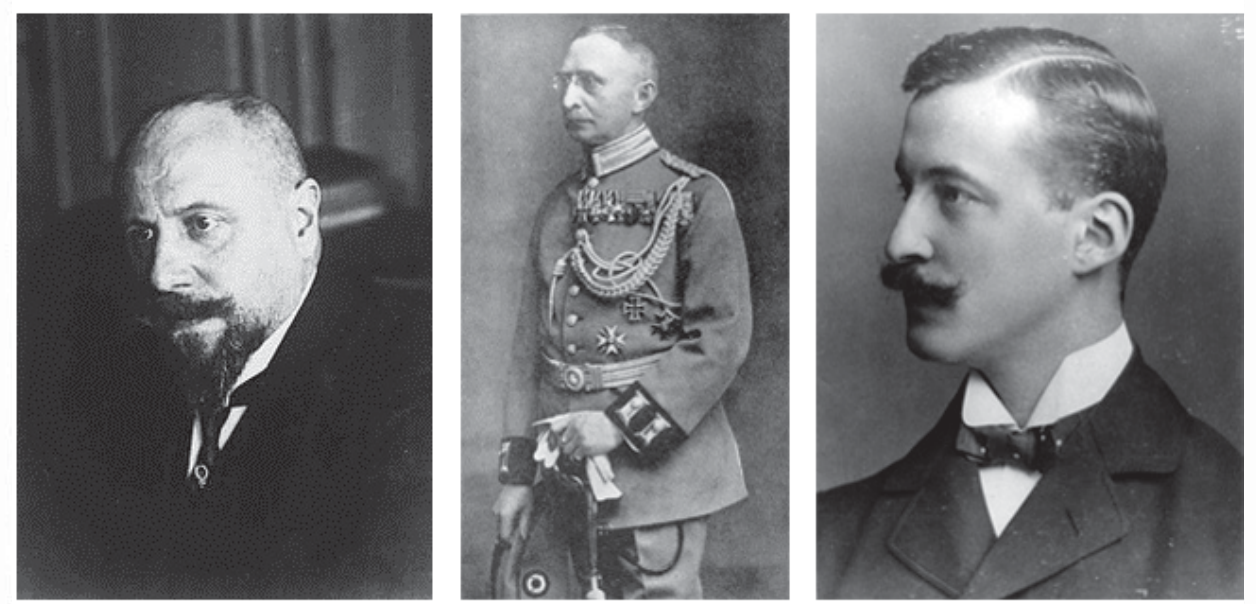

Karl Ebermaier (1862-1943) Karl Zimmermann (1864-1949)

Günther Tessmann (1884-1969)

en Barcelona, uno en Reus, uno en Flix, dos en San Cristóbal de Tosas (Gerona) y tres en Calonge (Gerona).

159 Embajador alemán príncipe de Ratibor a ministro de Estado, Amalio Gimeno (Madrid, 14-V-1916), en AHN, Asuntos Exteriores, Fondo Política, Serie I Guerra Mundial, leg. H.3050. Romanones dijo a Gimeno el 24-V que no le parecía oportuno autorizar esas visitas. Una lista de los 26 alemanes procedentes del Camerún internados en Madrid con socorro del Estado español, en AHN, Asuntos Exteriores, Fondo Política, Serie I Guerra Mundial, leg. H.3144. 
ALEMANES INTERNADOS PROCEDENTES DEL CAMERÚN (1916)

\begin{tabular}{|c|c|c|c|c|c|c|}
\hline Clase & Zaragoza & Pamplona & Aranjuez & Alcalá & Cádiz & TOTAL \\
\hline Mujeres & 14 & 1 & 6 & 0 & 0 & 21 \\
\hline $\begin{array}{c}\text { Niños menores } \\
\text { de } 17 \text { ańos }\end{array}$ & 7 & 0 & 2 & 0 & 0 & 9 \\
\hline $\begin{array}{c}\text { Misioneros } \\
\text { Médicos y p. } \\
\text { sanitario }\end{array}$ & 25 & 19 & 0 & 5 & 2 & 51 \\
\hline $\begin{array}{c}\text { Hombres } \\
\text { menores de } \\
\text { 55años }\end{array}$ & 302 & 197 & 24 & 157 & 5 & 685 \\
\hline $\begin{array}{c}\text { TOTAL } \\
\text { TOT }\end{array}$ & 356 & 217 & 38 & 164 & 18 & 783 \\
\hline
\end{tabular}

Fuente: Anexo al informe de la Subsecretaría de Guerra, $5^{\circ}$ Negociado, a ministro de Estado (Madrid, 30-V-1916), en AMAE, Fondo Política, Serie I Guerra Mundial, leg. H.3050.

A mediados de 1916, el Gobierno español solicitó al británico salvoconductos para que retornaran a Alemania los civiles y los miembros del personal sanitario, aunque estos últimos no partieron hacia la patria hasta fines de mayo de $1919^{160}$. En Alcalá, los prisioneros del Camerún vivieron primero en barracas,

160 Sección Política del Ministerio de Estado a embajador de Gran Bretaña (Madrid, 30-VI-1916), en AHN, Asuntos Exteriores, Fondo Política, Serie I Guerra Mundial, leg. H.3050. Se solicitó salvoconductos para 22 mujeres, ocho niños, 24 religiosos, 17 médicos, 40 miembros de personal sanitario y tres varones mayores de 55 ańos: en total 115 personas, tal como pidió Ratibor al ministro de Estado el 26-VI. En respuesta a una carta de 13-II, el 11-V-1918 el embajador británico señalaba que el personal sanitario no estaba cubierto por la Convención de Ginebra y que el Gobierno de S.M. "are unable to agree to the repatriation of the fifty five men referred to". Una nota del Departamento de Política del Ministerio de Estado (Madrid, 10-XII-1918), en AHN, Asuntos Exteriores, Fondo Política, Serie I Guerra 
y luego fueron autorizados a buscar alojamiento en la ciudad, a condición de presentarse a diario en las instalaciones de acogida, y luego por lo menos una vez al mes. Se les permitió corresponder con la población, tener libertad de movimientos en la localidad y que sus cartas no fueron sometidas a censura ${ }^{161}$. En Pamplona, los oficiales vivían en alojamientos particulares y los soldados en barracas. Todos fueron autorizados para moverse hasta un radio de cuarenta kilómetros, aunque tenían que presentarse periódicamente a las autoridades españolas. En el verano de 1918, hasta trescientos civiles alemanes que permanecían internados en Alcalá fueron autorizados a trabajar libremente e ir a Sevilla, donde serían alojados en casas particulares sin vigilancia ${ }^{162}$. Precisamente entonces, las autoridades militares de Las Palmas tomaron medidas para que dos artilleros náufragos del vapor inglés Heron Bridge (que había sido torpedeado por un submarino) también fueran internados. El embajador británico amenazó con que si se producía este internamiento de marineros que servían en un barco mercante armado con fines defensivos, exigiría el internamiento inmediato de los hombres de cada navío alemán o austriaco refugiado en puertos españoles, y presuntamente pertenecientes a la reserva del Ejército o de la Marina en su país de origen ${ }^{163}$.

Ante la lasitud de las medidas de control implementadas por el Gobierno español, comenzó a producirse un goteo incesante de fugas: el 6 de agosto de 1916 se escapó de Las Palmas de Gran Canarias Reinhold Badewitz, oficial del buque corsario SMS Möwe, que capitaneado por el conde von Dohna-Schlodien había hundido varios mercantes aliados a inicios de 1915. El 8 de febrero, este navío había apresado al Westburne, se refugió con este barco y las tripulaciones de otros navíos hundidos en Santa Cruz de Tenerife, y el 23 de febrero fue hundido

Mundial, leg. H.3050, recuerda que desde VIII-1916, a ruego de la Embajada alemana, se habían hecho gestiones por ese departamento para que fueran autorizados a volver a Alemania ciertas categorías de súbditos alemanes (misioneros, mujeres, médicos, etc.), la mayoría de la colonia de Camerún. Desde III-1917, los aliados consintieron la repatriación de varones menores de 15 años o mayores de sesenta, mujeres, médicos militares, sacerdotes y religiosos.

161 Agregado militar coronel Tillion a ministre de la Guerre, État Major de l'Armée, $2^{\mathrm{e}}$ Bureau (Madrid, 19-V-1916), en SHD, Guerre, leg. 7N 1201. El agregado militar francés había visitado el día anterior el campo de internamiento de Alcalá de Henares con el jefe del contraespionaje británico mayor Charles Julian Thoroton, con el propósito de conocer el régimen de los militares alemanes que permanecían en el Camerún. Las instrucciones referentes al trato a los militares internados (alojamiento, atención sanitaria, disciplina, entierros, etc.) estaban copiadas de la Dirección del Servicio Territorial Suizo (Berna, 25-IV-1915), en AHN, Asuntos Exteriores, Fondo Política, Serie I Guerra Mundial, leg. H.3012, exp. 6.

162 Informes de 3-VII y 1-VIII-1918, en SHD, Marine, leg. SS XC 6.

163 Protesta del embajador británico Arthur H. Hardinge a Dato (Madrid, 3-VI-1918), en SHD, Marine, leg. SS XC 17. 
por su propia marinería ante el acoso del acorazado HMS Sutlej. Tras quedar internado junto otros marinos, Badewitz aprovechó su situación de semilibertad para disfrazarse de jesuita y embarcar en un mercante de bandera neutral con destino en Cádiz, donde a su llegada fue recogido por el $U-35$ y trasladado a Pola (TOJO RAMALLO y TOJO GONZÁLEZ, 2008: 481-482).

En octubre de 1916 comenzaron a evadirse los primeros internados de los depósitos de Alcalá y Pamplona ${ }^{164}$. Se produjeron algunas fugas rocambolescas, como la que protagonizaron en Vigo veinte oficiales alemanes (cinco del depósito de Pamplona y siete del de Alcalá, a los que se unieron otros ocho internados en Vigo: cuatro de ellos oficiales del mercante refugiado Goeben y uno del Woert) en la goleta Virgen del Socorro, pesquero de matrícula de Corcubión que había sido adquirida por 11.150 pesetas por el segundo oficial del Goeben con el apoyo del agregado naval Hans von Krohn, su ayudante Willbrandt, el gobernador imperial Karl Ebermaier, el secretario del consulado en Vigo Kindling, un estudiante en leyes llamado Hans Reupke y varios espías de identidad desconocida. El artífice del plan fue Karl Koch, un oficial de 34 años internado en Pamplona. Los fugitivos, que habían llegado en pequeños grupos a la ciudad gallega y se habían diseminado en hoteles y casas de huéspedes, fueron acercándose al puerto durante las noches del 5 y el 6 de octubre de 1916, y tras transbordar víveres a la embarcación que estaba acostada al mercante internado Woert, la abordaron a la dos de la madrugada del día 7 con la intención de atravesar el Canal de la Mancha y ganar las costas de Bélgica u Holanda bajo al protección del pabellón neerlandés. Aunque el cónsul francés tenía noticia de la llegada de un grupo sospechoso y participó de ella a las autoridades militares españolas, la goleta logró zarpar. Tras sufrir el día 24 una fuere tormenta que provocó graves daños en el casco y la arboladura de la goleta a unas trescientas millas al Oeste de Bantry, los fugados renunciaron a ir a Noruega por Escocia y optaron por atravesar el Canal de la Mancha. La Virgen del Socorro acabó por ser apresada el 8 de noviembre cerca de East Goodwin por el pesquero artillado británico Paramount, que identificó

164 Minuta del marqués de Lema al ministro de la Guerra (Madrid, 22-VI-1917), en AHN, Asuntos Exteriores, Fondo Política, Serie I Guerra Mundial, leg. H.3050, sobre la evasión de Alcalá del militar internado Armand Seckamp. Se interesó también a la Dirección General de Seguridad para que lo capturase. Se produjeron otras ocho huidas de Pamplona el 9-X-1916. Ante la sucesión de evasiones, el ministro de la Guerra avisó al presidente del Consejo marqués de Alhucemas (Madrid, 7-XII-1917), en AHN, Asuntos Exteriores, Fondo Política, Serie I Guerra Mundial, leg. H.3050 que había ordenado a las autoridades militares que extremasen la vigilancia, advirtiendo a los internados que toda tentativa de evasión se castigaría con privación de la libertad de movimientos. 
y detuvo a la tripulación y condujo la goleta a Ramsgate. Los gastos finales de la frustrada expedición ascendieron a 18.000 pesetas $^{165}$. La recuperación de los militares internados en Espańa siguió siendo una prioridad para el Gobierno alemán: en julio de 1918, 37 súbditos germanos fueron enviados en un lanchón a 17 millas de las islas Cíes, donde les esperaban dos submarinos ${ }^{166}$, pero en agosto, a la vista de la delicadísma situación política con España por culpa de los hundimientos de barcos mercantes sin previo aviso, el Admiralstab no se mostró conforme con el proyecto de Steffan de evadir más oficiales alemanes por submarino desde Barcelona ${ }^{167}$.

Según datos procedentes de la inteligencia naval francesa, en Fernando Poo permanecieron internados sesenta oficiales y suboficiales, y 5.600 tiradores indígenas, más de 10.000 boys, mujeres y niños ${ }^{168}$. En un largo memorando reservado enviado el 19 de diciembre de 1916 por el gobernador general Barrera al Ministro de Estado se relatan las penalidades de los alemanes a la llegada a Guinea. En esa fecha aún quedaban en los campamentos de la colonia española 5.649 soldados, 4.341 mujeres, 967 muchachos hermanos de soldados, 292 boys y 525 niños, "habiendo nacido aquí 124, de los que 29 están ya contados entre los muertos, o sea un total en los campamentos de 11.774 personas"169.

La seguridad del Golfo de Guinea siguió siendo motivo de preocupación para los aliados hasta el final de la guerra. El 23 de octubre de 1916, el embajador francés Léon Geoffray denunció al ministro de Estado Amalio Gimeno que el día 15 un comandante alemán internado en Fernando Poo había dicho a sus soldados indígenas que en dos meses volverían al Camerún, y que para tal fin habían llegado a la isla varias cajas con 2.400 rifles y abundante munición que habían ido a parar al campo de internamiento donde aún se encontraban los oficiales alemanes, por lo que se volvió a requerir su urgente internamiento en

165 Véanse "Extraordinaria evasión de alemanes. Cómo se escaparon 20 oficiales de Pamplona y Alcalá”, El Liberal, 3-I-1917 y Arthur H. Hardinge a Amalio Gimeno (Madrid, 18-III-1917), en AHN, Asuntos Exteriores, Fondo Política, Serie I Guerra Mundial, leg. H.3050. Igualmente, TOJO RAMALLO y TOJO GONZÁLEZ (2008), pp. 483-490.

166 "Fuga de 37 alemanes", El Sol, 25-VII-1918.

167 Carpeta "Caramba”, no 608 (17-VIII-1918), en SHD, Marine, leg. SS Q 56.

168 Agregado naval Robert de Roucy a Ministère de la Marine (Madrid, 31-X-1916), en SHD, Marine, leg. SS XC 5.

169 Antonio Barrera al Ministro de Estado (19-XII-1916), en AHN, Asuntos Exteriores, Fondo Política, Serie I Guerra Mundial, leg. H.3162. 
España y el regreso de los 15.000 soldados nativos al Camerún ocupado ${ }^{170}$. En una nota del 23 de octubre se ordenó al almirante Louis Jaurès (comandante de la división naval del Atlántico y el África Occidental a bordo del acorazado Kléber) y al comandante de Marina de Dakar que enviaran a radas francesas a todos los buques que fueran a la Guinea española, para visitarlos minuciosamente con el objeto de encontrar armas de contrabando. Como se ha visto anteriormente, hubo frecuentes interceptaciones y registros por parte francesa de los vapores que unían Fernando Poo con Guinea y otras colonias cercanas. Amalio Gimeno prometió el envío de dos barcos para trasladar a España a los alemanes que seguían refugiados en Guinea, pero la ejecución del acuerdo se fue demorando. Los diplomáticos aliados denunciaban que el gobernador general Ángel Barrera —al que periódicos como el Heraldo de Madrid y el lerrouxista El Diluvio reputaban como germanófilo por sus relaciones con comerciantes locales como Otto Kruhnert-y el comandante militar Manuel Giménez Pidal confraternizaban con sus presuntos retenidos. La situación se crispó a tal extremo que el 28 de octubre de 1916 los cruceros Astraea (inglés) y Surcouf (francés) hicieron una demostración naval frente a las costas de Santa Isabel para urgir el envío a España de los internados del Camerún, señalando que tenían noticias fidedignas de que los alemanes disponían de fusiles y municiones en sus campamentos ${ }^{171}$. $\mathrm{Al}$ acudir los comandantes aliados a visitarle, el gobernador de Fernando Poo protestó enérgicamente cuando éstos le entregaron una carta diciendo estar informados de que Romanones había hecho la promesa formal de transportar sin demora a Espańa a los internados, y le preguntaron a guisa de ultimátum por los hombres, grados, fecha de salida y nombre barco que les transportaría, para evitar su torpedeamiento. Los comandantes trataron incluso de ir a los campamentos y tomar fotografías de los refugiados, pero se

170 Un informe del embajador Arthur H. Hardinge (Madrid, 29-X-1916), en AGA, Asuntos Exteriores, Embajada en París, leg. 54/5948 confirma que los oficiales alemanes internados en Fernando Poo habían anunciado recientemente a sus soldados indígenas la próxima reconquista militar del Camerún.

171 En nota de Hardinge a ministro de Estado (Madrid, 30-I-1918), en AHN, Asuntos Exteriores, Fondo Política, Serie I Guerra Mundial, leg. H.3162 se atacaba duramente al gobernador Barrera con un memorando donde se destacaba su germanofilia, su rechazo de los ultimátums ingleses para la deportación de los alemanes y la perfecta compenetración existente entre los oficiales espańoles y germanos. Barrera rechazó la acusación de que los alemanes internados portaran armas, y advirtió que la mitad estaban enfermos. Los problemas con los aliados (detención de alemanes, control del contrabando, asesinato de dos colonos que acababan de pasar a la parte española ) del gobernador de Guinea, en OLIVAR BERTRAND (1956), pp. 7-10 y 25-31. 
lo impidió la guardia ${ }^{172}$. El 30 de octubre, el embajador francés apremió para el envío a la península de los oficiales alemanes, aportando incluso barcos propios para efectuar la operación. El 7 de noviembre, el gobernador general de Guinea negó todas las acusaciones, y cinco días más tarde el ministro Gimeno protestó formalmente por el desvío de los buques mercantes españoles como el Ciudad de Cádiz hacia Senegal, justificando la presencia de oficiales alemanes en la necesidad de mantener la disciplina entre los soldados indígenas, pero siempre a las órdenes de las autoridades españolas ${ }^{173}$. El incidente no se zanjó de forma inmediata, puesto que en diciembre el Gobierno británico elevó una nueva nota de protesta por la irregular situación de las tropas alemanas refugiadas en la colonia (ROMERO SALVADÓ, 1999: 85-86), lo que obligó al Gobierno español a enviar a Guinea el 30 de diciembre una compañía de las Fuerzas de Protección de Infantería de Marina en previsión de un levantamiento o motín de los prisioneros. Los soldados nativos acabaron por retornar al Camerún en 1917, pero los oficiales alemanes permanecieron retenidos en la colonia española hasta más allá del final de la guerra, lo que motivó nuevas protestas francesas por la no devolución de la totalidad de las tropas enemigas internadas en Fernando Poo, decisión de la que culpaban al gobernador general Barrera ${ }^{174}$. La presión diplomática de la Embajada británica en Madrid fue tan insistente que en mayo de 1918 el ministro de Estado Eduardo Dato concedió a Barrera un permiso de larga duración que le mantuvo alejado del Camerún hasta el final de la contienda. Su ejecutoria, ciertamente personalista pero nada rígida, le valió una condecoración alemana por su actitud humanitaria hacia los refugiados del Camerún, además de un reconocimiento tardío de los aliados. Según una nota referente a la repatriación de los indígenas internados en Fernando Poo entregada al Ministerio de Estado a mediados de 1919 por el embajador francés Gabriel-Ferdinand Alapetite: "Mon gouvernement en effet ne s'était pas opposé au retour du gouverneur général Barrera à Fernando Poo parce que le Gouvernement de Sa Majesté lui avait donné l'assurance que sous sa direction les opérations de rapatriement des indigènes de

172 Amalio Gimeno a embajador en Londres (Madrid, 8-XI-1916), en AGA, Asuntos Exteriores, Embajada en París, leg. 54/5948.

173 Véanse Gimeno a embajador en Londres Alfonso Merry del Val (Madrid, 8-XI-1916) y Ministère des Affaires Étrangères a León y Castillo (París, 15-XI-1916), en AGA, Asuntos Exteriores, Embajada en París, leg. 54/5948.

174 Ministère des Affaires Étrangères, Direction Politique Afrique a embajador José Quiñones de León (París, 21-II-1918), en AGA, Asuntos Exteriores, Embajada en París, leg. $54 / 5948$. 
Cameroun seraient menées rapidement à bonne fin"175. La mayor parte de estos nativos fue repatriada entre agosto y diciembre de 1919, pero muchos se negaron a partir y permanecieron como trabajadores en Fernando Poo.

A fines de 1918, entre 500 y 600 alemanes seguían retenidos en España, de los cuales unos doscientos procedían del Camerún y el resto eran tripulantes de los diversos submarinos y mercantes internados ${ }^{176}$. Con el final de la guerra, la mayor parte regresaron a la patria (el propio Ebermaier retornó al Reich a fines de 1919), pero un contingente no determinado optó por permanecer en España. A partir de octubre 1919, los refugiados alemanes fueron autorizados a solicitar el correspondiente permiso de residencia. Muchos de ellos, que habían encontrado trabajo o habían entablado relaciones con ciudadanos españoles, prefirieron rehacer su vida en el país que les había dado precario cobijo durante la contienda.

175 Informe del embajador francés Gabriel-Ferdinand Alapetite (Madrid, 18-VI-1919), en AHN, Asuntos Exteriores, Fondo Política, Serie I Guerra Mundial, leg. H.3051.

176 Telegrama del encargado de negocios en Madrid Émile Dard (11-XII-1918, 20:10 h.), en SHD, Guerre, leg. 6N 135. Según varios informes fechados entre el 13-I y el 22-II-1919, en AHN, Asuntos Exteriores, Fondo Política, Serie I Guerra Mundial, leg. H.3144, por esas fechas había 31 oficiales y marineros del Crefeld internados en Santa Cruz de Tenerife; 60 marineros (44 de ellos del Kaiser Wilhelm der Grosse, y el resto de otros cruceros auxiliares) en Gran Canaria; 280 en la 6a Región Militar (213 en Pamplona y uno en Graus, además de otros 66 con permiso: cuatro en Sevilla, uno en Murcia. tres en Barcelona, uno en Valencia, uno en Reus, uno en San Sebastián, uno en Puente la Reina cuatro en Madrid, 35 en Santander $\bigotimes$ de los cuales nueve de la tripulación del submarino UC-56 y 26 civiles $\bigotimes$, uno en Segovia, uno en Maliańo, siete en Polanco, dos en Santońa, uno en Frómista, uno en Castro

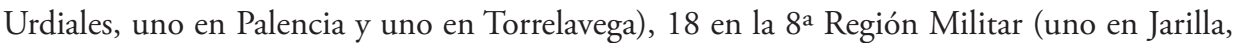
cuatro en León, cuatro en Astorga y nueve en Ferrol, cinco de los cuales pertenecían a la tripulación de $U C-48$ y cuatro a la del $U-23)$. En el cuartel de San Antonio de Granada permanecían retenidos 76 alemanes y seis austriacos. 


\section{ARCHIVOS}

AGA Archivo General de la Administración (Alcalá de Henares).

AHN Archivo Histórico Nacional (Madrid).

SHD Service Historique de la Défense (Château de Vicennes, París).

\section{BIBLIOGRAFÍA}

BLANCA CARLIER, J.M. (1976), "La Primera Guerra Mundial y la flota mercante española”, Revista General de la Marina, no 191, agosto-septiembre, pp. 133-160.

BORDEJÉ Y MORENCOS, F. de (1978), Vicisitudes de una política naval. Desarrollo de la Armada entre 1898 y 1936, Madrid, San Martín.

DANE, E. (1919), British Campaigns in Africa and the Pacific, 1914-1918, Londres, Hodder and Stoughton.

HOFFMANN, F. (2006): "Als letzter deutscher Gouverneur in Kamerun: Karl Ebermaier (1862-1943)", Geschichte im Wuppertal, no 15, pp. 18-27 [http://www.bgv-wuppertal.de/GiW/Jg15/3Ebermaier.pdf].

MOBERLY, F.J. (1931), Military Operations Togoland and the Cameroons 1914-1916, Londres, HMSO.

NERÍN, G. (2010), La última selva de España. Antropófagos, misioneros y guardias civiles, Madrid, Los Libros de la Catarata.

OLIVAR BERTRAND, R. (1956), "Repercusiones en España de la Primera Guerra Mundial”, Cuadernos de Historia Diplomática, no 3, pp. 3-49.

ROMERO SALVADÓ, F.J. (1999), España, 1914-1918. Entre la guerra y la revolución, Barcelona, Crítica.

TOJO RAMALLO, J.A. y TOJO GONZÁLEZ, S. (2008), Cazadores de Barcos. Historia de los submarinos alemanes en las costas de Galicia durante la Primera Guerra Mundial, Madrid, Ministerio de Defensa. 